\title{
Factors Affecting Subjective Norms in use and have a Private Vehicle in Makassar, Indonesia
}

\author{
${ }^{1}$ Maryam Hafram and ${ }^{2}$ Abdul Hafid Hasim \\ ${ }^{1}$ Department of Civil Engineering, Universitas Muslim Indonesia, \\ Urip Sumohardjo km 5 Street, 90231 Makassar, Indonesia \\ ${ }^{2}$ Department of Civil Engineering and Planning, Universitas Negeri Makassar, \\ 90224 Mallengkeri Raya Street, Makassar, Indonesia
}

\begin{abstract}
Private vehicles are already a major requirement to carry out daily activities. The extent to which the influence of beliefs and motivations on subjective norm in meeting transportation needs in Makassar. Questionnaires were used to obtain primary data in the study, the survey contained questions related to the personal aspects of subjective norms that influenced the beliefs and motivations of respondents who chose to use private vehicles whether cars or motorcycles. Then, the sample used amounted to 200 to be distributed using a random proportional random sampling method adjusted at the level of education, age and monthly income. The analysis used is multiple regression descriptions, it used with SPSS Program. The result is that there is significant influence between normative belief to attitude with a coefficient value of 0.631 and there is the impact of motivation on the position with a ratio value equal to 0.648 . Of the two independent variables indicate the influence of a large enough person in choosing a private vehicle. The greater power comes from within the family of both parents, wife, husband and child. The other influence is the social status that forces a person to own a private vehicle.
\end{abstract}

Key words: Private vehicle, belief, motivation, influence, questionnaires, significant, SPSS

\section{INTRODUCTION}

Developing countries with low public transport forced residents to use private vehicles that caused high levels of ownership of private vehicles. High growth causes vehicle congestion problems (Petersen and Schafer, 2004)

The main problem faced by developing countries in the world related to transportation conditions resulting in social, economic and environmental losses is enormous. The higher the level of losses will be given the poor infrastructure and transportation systems and the low traffic law enforcement.

The number of motor vehicles in 2016 is $1,425,151$ units or 87,009 units increased compared to 2015. While in 2014 the number of motor vehicles in Makassar is only about 1,255,755 units. That is in the last 2 years there has been an increase of 172,395 units. When calculated on average, car growth in Makassar ranges between $7 \%$ per annum. The rate of growth mastered by two wheels that will penetrate one million units by 2014 (Kurniawan, 2017).

Car disclosure has generated significant social changes regarding improving the quality of life of citizens and greater efficiency of their journey. However, the use of motor vehicles has led to some issues such as environmental pollution, increased respiratory illness and the high cost of road infrastructure. Vehicles are the primary source of pollution and carbon monoxide emissions in the city (Sempere and Riechmann, 2000). Asymmetry, the adverse effects of urban traffic noise are evident with particular attention to attentive processes, verbal communication, sleep and Emotional response model of individuals (Miedema, 2007)

Subjective norms as different perceptions of social pressure to commit or engage in behaviors. The subjective criterion determined by the normative belief and the motivation to comply. The legal conviction is a conviction about the agreement or disapproval coming from the referent. The motivation to observe is the motivation of individuals to meet the expectations of the referent. People who believe that a leader will support a behavior will feel social pressure for behavior and vice versa (Ajzen, 2005).

A subjective norm reflects the perception of a person who has most of the people who are important to him that he or she should or should not conduct the behavior in

Corresponding Author: Maryam Hafram, Department of Civil Engineering, Universitas Muslim Indonesia, Urip Sumohardjo km 5 Street, 90231 Makassar, Indonesia 
question. The more an individual perceives that other significant people think that he or she should participate in the performance, the higher the motivation of a person to meet with others (Ajzen and Fishbein, 1980).

The basis of the formation of only intentions is not just for them attitudes towards behavior and results but also in their perception of the ease of action and social pressures felt by others that are significant to them. The combined force of these three factors (attitude, perceived behavioral control and social norms) determines the power of intent to perform target behavior. Faced with multiple competitive alternatives (for example, the choice of travel arrangements). The conventional theory suggests that individuals choose the conduct for which they have the greatest willpower (Bamberg et al., 2011).

Massive use of automobiles causes serious problems for environmental quality, quality of urban life and accessibility of different destinations. In addition to technological solutions, practical solutions to car related issues require reductions in vehicle traffic volume, based on changes in the behavior of individual motorists (Steg and Gifford, 2005).

Needs a proper understanding of the reasons for the use of the car, since, policy measures aimed at managing transport demand will be particularly effective when addressing the significant factors affecting the level of use of the car (Steg, 2005).

\section{MATERIALS AND METHODS}

Questionnaires were used to obtain primary data in the study, the survey contained questions related to the personal aspects of subjective norms that influenced the beliefs and motivations of respondents who chose to use private vehicles whether cars or motorcycles. Then, the sample used amounted to 200 to be distributed using a random proportional random sampling method adjusted at the level of education, age and monthly income.

Table 1 shows that after analyzing the data, the results of the majority of respondents with male gender of $63.50 \%$ (127 of 200 respondents), an undergraduate level of $52.50 \%$ (105 of 200 respondents). Then, the age of majority of respondents between $41-50$ years is $49.50 \%$ (99 of 200 respondents) and monthly income earned between IDR 3,000,000-4,000,000 is 63.50\% (127 of 200 respondents).

When considering two or more variables, we can extend the correlation and regression analysis to account for these variables but suppose that the relation between the variables is linear. The value of the correlation coefficient indicates the strength of the ratio and the regression value can be used to predict the value of the
Table 1: Demographic profile of the respondents $(\mathrm{N}=200)$

\begin{tabular}{lrr}
\hline Categories & Frequencies & Percentage \\
Gender & 127 & \\
Man & 73 & 63.50 \\
Women & & 36.50 \\
Level of education & 12 & \\
Junior high school & 34 & 6.00 \\
Senior high school & 105 & 17.00 \\
Bachelor & 49 & 52.50 \\
Master & & 24.50 \\
Age (years) & 11 & \\
20-30 & 36 & 5.50 \\
$31-40$ & 99 & 18.00 \\
41-50 & 54 & 49.50 \\
51-60 & & 27.00 \\
Monthly income (IDR) & 23 & \\
2,000.000-3,000.000 & 127 & 11.50 \\
3,000.000-4,000.000 & 42 & 63.50 \\
4,000.000-5,000.000 & 8 & 21.00 \\
Above 5,000.000 & & 4.00 \\
\hline
\end{tabular}

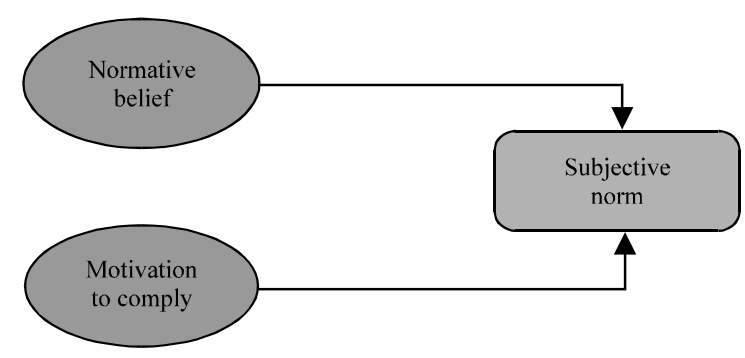

Fig. 1: Normative belief and motivation to comply against subjective norm

dependent variable using the value of the independent variable. From the multiple regression descriptions, it used with SPSS program (Hinton et al., 2014) (Fig. 1).

\section{RESULTS AND DISCUSSION}

Assumptions and conditions: There are many assumptions to consider but we will focus only on the main ones that easily tested. These are the ratio between each of the predictors and the dependent variable is linear, errors usually distributed and the residual variance (the difference between current and predicted scores) is constant (Morgan et al., 2012).

The scatterplot of standardized residuals against the standardized predicted values shows no clear relationship pattern between the residuals and the predicted values. This is consistent with the assumptions of linearity and homoscedasticity. From the typical P-P plot of standardized residuals, it can be seen that the plot of the residuals for the dependent variable fits the familiar pattern well enough to indicate a relatively normal distribution. To test the assumption of independence of error terms (residuals) used Durbin-Watson statistic. As 
$\underline{\text { Table 2: Model summary dependent variable }}$

\begin{tabular}{lccc}
\hline $\mathrm{R}$ & $\mathrm{R}^{2}$ & Adjusted $\mathrm{R}^{2}$ & Durbin-watson \\
\hline 0.577 & 0.333 & 0.326 & 1.654 \\
\hline
\end{tabular}

Table 3: ANOVA dependent variable

\begin{tabular}{lrcc}
\hline Models & df & F-value & Sig. \\
\hline Regression & 2 & 49.105 & 0.000 \\
Residual & 197 & & \\
Total & 199 & & \\
\hline
\end{tabular}
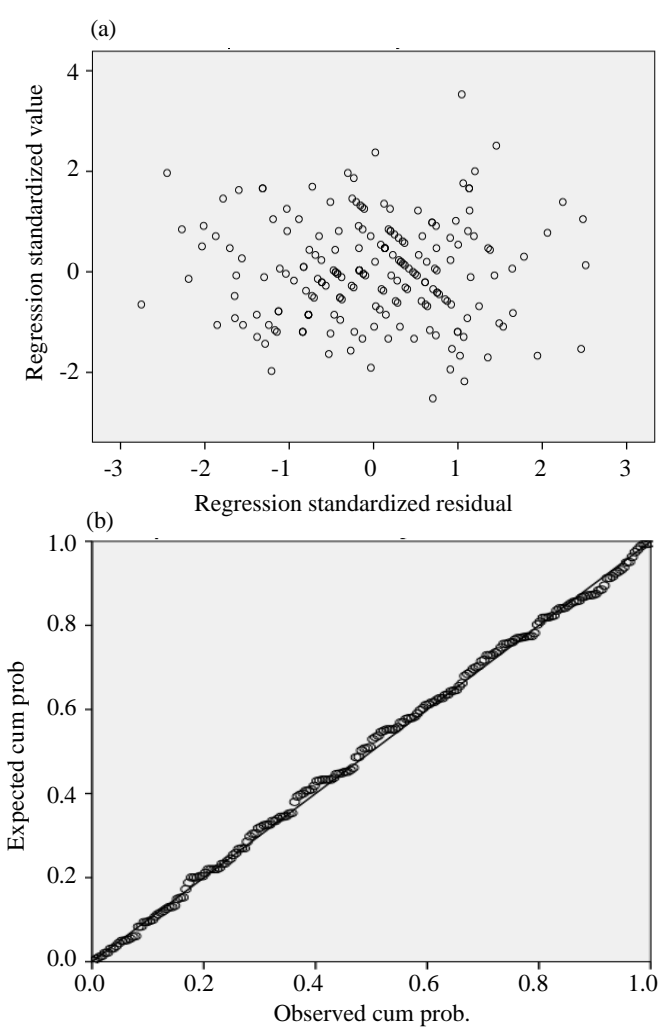

Fig. 2: a) Scatterplot regression standardized residuals (dependent variable: subjective norm) and $b$ ) Normal P-P plot of regression standardized residuals

the Durbin-Watson (Table 2) $d=1.654$ is between the two critical values of $1.5<\mathrm{d}<2.5$, it can assume that there is the independence of residuals (Ho, 2014) (Fig. 2).

The summary model shows that the value of multiple correlation coefficients (R), using all predictors simultaneously obtained by 0.577 and the adjusted $\mathrm{R}^{2}$ value obtained for 0.326 (Table 2). Such circumstances suggest that the model can explain 33\% of the variance in subjective norms. This result is a significant effect (Cohen, 1988).

The ANOVA shows that the $F$ value is 49.105 and Sig. are 0.000 (Table 3 ). These results indicate that predictors in this case, normative belief and motivation to comply significantly can both be used to predict subjective norms of vehicle users.
Table 4: Coefficients dependent variable

\begin{tabular}{lccc}
\hline Variables & Standardized coefficients & $\mathrm{t}$-values & Sig. \\
\hline Normative belief & 0.631 & 5.106 & 0.000 \\
Motivation to comply & 0.648 & 5.366 & 0.000 \\
\hline
\end{tabular}

The significance level of the one-sided coefficient of output (measured by probability) yields a value of 0.000 (Table 4). Since, the probability is far below 0.05 the correlation is very significant/real (Santoso, 2014). Then, from the description, we can conclude that the independent variable of the regulatory belief has a significant effect on the normative understanding dependent variable with a coefficient of 0.631 . Independent variables are also motivation to comply to have a significant effect on the dependent variable of the standard personal value of the ratio of 0.648 .

Based on the results obtained from the analysis Table 4 shows that the influence of belief (normative belief) on the subjective norm is large in this case, the influence in convincing to use private vehicles as the primary mode of transportation. These views come from families; parents are more confident that by giving private vehicles rather than choosing to use public transit to their children will be cheaper and easier. Especially, considering the existing spatial condition in Makassar, between school/campus or workplace with residential zone if using public transportation requires 2-3 times the transfer of transport type to get to the destination place.

Private vehicles in Makassar have become a primary requirement in everyday life. We can see that each house has at least one private two-wheeled vehicle (motorbike) besides because it is still more expensive and ineffective when using public transportation in addition to being expensive and in its use every individual must walk to the highway that passes through the public transport. The absence of restrictions on vehicle ownership results in the type of vehicle owned by each and family more diverse, the use of vehicles tailored to the needs or activities undertaken. We will be able to see a house can have more vehicles than the number of residents of the home. There is a tendency that motivates in fulfilling the needs of driving is within the family itself, either from spouses, parents or the needs of children.

As for other motivations why individuals choose to use private vehicles, i.e., social status. Someone will feel embarrassed and arise a sense of inferiority if they do not have a car or private motor vehicle while the neighbors have it. Although, private vehicles are rarely used but having them will improve the social status between friends.

Transport users are more likely to see social factors and demographic conditions of the region in determining the choice of transportation mode to be used. A 
number of researchers have shown that age, sex, socioeconomic status or income level, education level, household composition and vehicle ownership are factors that play a significant role in influencing vehicle user's behavior (Lleras et al., 2003; Timmermans et al., 2003; Morikawa et al., 2003; Soehodho et al., 2012)

In this research, enough to see that the influence of motivation in having a large enough vehicle in addition to the need for activity but the social factors that become the key determinant why individuals choose to use private vehicles. Factor age one of the only, the tendency of people whose age entered in the category of the physical condition has declined more choose to use private vehicles, especially, cars. The belief that cars are safer and more comfortable to use is one of the factors in which the use of cars for older age is getting bigger.

In particular, it has shown that age has a significant correlation with the choice of transport. For example, young people and parents will be more likely to use public transport than private cars on the go. Probably because people can not legally obtain the driving license at a certain age while older adults may have limited driving ability due to age-related sight loss or weaker response reflexes (Pucher and Renne, 2003)

About revenue, it has shown that people with higher incomes are more likely to drive than those with lower incomes, although both groups live in the same locations with similar access infrastructures. A possible explanation for this result is having higher income increases the ability to own and drive a car (Dargay and Hanly, 2007; Pucher and Renne, 2003).

One of the most important aspects of meeting transportation needs is the individual income factor. The easier it is to get a private vehicle due to the more different car prices than the ease of payment and discounts given by the seller of the vehicle.

Of course, these results do not indicate that policy measures with the goal of influencing the practical use of the car as the cost, time will not be enough. Strategies such as making car prices more expensive to buy can be very helpful in managing travel demand. However, such action is not easy to implement because people firmly refuse to work. This may be affecting symbolic and affective car use features. It is possible that policymakers should consider mitigating these adverse consequences by applying accompanying measures to compensate for any loss of symbolic and emotional values. These results also indicate that policy should adapt to a particular target group. It is effective to evaluate different groups and different symbolic aspects that need to considered when developing policies (Steg, 2005).

Using a car is much more appealing than public transport because of its convenience, independence, flexibility, speed, reliability and more fun. The car also improves the social status of its users over public transport. However, traveling by public transport is considered safer than driving a car (Steg, 2003).

At the same time, however, other research results question some aspects of causal structure postulated by the proposed behavioral theory. Thus, the relationship between normative beliefs, behaviors and controls associated with the use of transportation means and the overall attitudes, norms and perceived behavioral control over these means of transportation seem more complicated than postulated by planned theory. Changes in behavioral outcomes such as "cheap", "fast" or "comfortable" do not appear to affect just the attitude as postulated by planned theory but also subjective norms. And trust controls not only influence the control of perceived behavior but personal attitudes and norms as well. Student attitudes and perceived social support for the use of particular means of transportation appear to be "colored" by different types of cognitive beliefs simultaneously (Bamberg and Schmidt, 2001). The assumption that the subjective norm is a truly independent theoretical construct is still questionable from the research undertaken in this case the results obtained differ (Ajzen and Fishbein, 1980). Other authors have also questioned this assumption in planned behavioral theory differentiates between three types of trust behavior, normative and control and between the related construct attitudes, subjective norms and perceived behavior control. The need for this distinction, especially, the distinction between normative and normative beliefs (and between individual attitudes and standards) is questionable (Liska, 1984; Miniard and Cohen, 1981). Thus, technical clarification associated with the process underlying the establishment of norms and personal attitudes is indispensable.

Women, young people, low-income groups and parents use their cars less often than men, older age groups, high-income groups and spouses and families. The use of cars evaluated is far more active than public transport (except for traffic safety), even in densely populated Holland where public transportation is widely available. Assessment is almost in all aspects of car use positively, although, car use is considered expensive. In contrast, the evaluation of public transport aspects of the results tends to be negative or neutral, apart from traffic safety. In particular, after being evaluated, it is found that individuals who drive a car are more confident than travelers who travel by public transport in almost every way (Steg, 2003).

They evaluate the effects of the various transportation plans on sustainability. This implies the need to consider a wider range of sustainability indicators as changes in current transport systems may affect other sectors contribute to sustainable development (such as 
employment levels in the industry). They have developed several methods and models to evaluate the economic, social and environmental consequences of transport plans. However, currently only these are considered as some social indicators due to the lack of knowledge and precise methods, tools and techniques for assessing significant social impacts (Steg and Gifford, 2005).

A much more detailed study of transportation conditions is a social crisis associated with the morphological structure of the population that becomes a more serious and more complex issue where the development and the conditions of the population in developing countries are increasingly dynamic and increasingly difficult to predict related to the primary needs.

The process in meeting the needs of the community where at present the environmental conditions will depend on the economic conditions of the community. This is an attempt to ensure that quality of life will be better from time to time. Governments as regulators should be more biased to make sure they are achieved by making visible rules immediately.

\section{CONCLUSION}

The use of private vehicles is still the best short-term solution for cities such as Makassar. Not integrated, less comfortable and safe public transportation and the belief and motivation of individual car users that only with this daily activities can be done well and efficiently. Then besides that, there is an interesting factor that is increased social status when having a personal vehicle. By looking at the phenomenon mentioned above need to do further research related to what factors affect the users of private vehicles are willing to use public vehicles that have rarely used.

\section{REFERENCES}

Ajzen, I. and M. Fishbein, 1980. Understanding Attitudes and Predicting Social Behavior. Prentice-Hall, Englewood Cliffs, New Jersey, ISBN-13: 978-0139364358, Pages: 278.

Ajzen, I., 2005. Attitudes, Personality and Behavior. McGraw-Hill Education, UK., ISBN-13: 9780335224005, Pages: 192.

Bamberg, S. and P. Schmidt, 2001. Theory-driven subgroup-specific evaluation of an intervention to reduce private car use. J. Appl. Social Psychol., 31: 1300-1329.

Bamberg, S., S. Fujii, M. Friman and T. Garling, 2011. Behaviour theory and soft transport policy measures. Transp. Policy, 18: 228-235.
Cohen, J., 1988. Statistical Power Analysis for the Behavioral Sciences. 2nd Edn., Lawrence Erlbaum Associates, Hillsdale, New Jersey, USA., Pages: 567.

Dargay, J. and M. Hanly, 2007. Volatility of car ownership, commuting mode and time in the UK. Transp. Res. Part A. Policy Pract., 41: 934-948.

Hinton, P.R., I. Mcmurray and C. Brownlow, 2014. SPSS Explained. 2nd Edn., Routledge, New York, USA., ISBN:978-0-415-61601-0, Pages: 372.

Ho, R., 2014. Handbook of Univariate and Multivariate Data Analysis with IBM SPSS. 2nd Edn., CRC Press, New York, USA., ISBN:978-1-4398-9021-9, Pages: 547.

Kurniawan, T.Y., 2017. [Vehicle growth in Makassar average 7 percent each year]. Warta Ekonomi, South Jakarta, Indonesia.

Liska, A.E., 1984. A critical examination of the causal structure of the Fishbein/Ajzen attitude-behavior model. Social Psychol. Q., 47: 61-74.

Lleras, G.C., A. Simma, M.E.B. Akiva, A. Schafer and K.W. Axhausen et al., 2003. Fundamental relationships specifying travel behavior: An international travel survey comparison. Proceedings of the 82nd Annual Conference on Transportation Research Board, January 12-16, 2003, National Academies of Sciences, Engineering and Medicine, Washington, USA., pp: 1-19.

Miedema, H.M.E., 2007. Adverse Effects of Traffic Noise. In: Threats from Car Traffic to the Quality of Urban Life: Problems, Causes and Solutions, Garling, T. and ?L. Steg (Eds.). Elsevier, Amsterdam, Netherlands, ISBN:9780080448534, pp: 53-77.

Miniard, P.W. and J.B. Cohen, 1981. An examination of the Fishbein-Ajzen behavioral-intentions model's concepts and measures. J. Exp. Social Psychol., 17: 309-339.

Morgan, G.A., N.L. Leech, G.W. Gloeckner and K.C. Barrett, 2012. IBM SPSS for Introductory Statistics: Use and Interpretation. 5th Edn., Routledge, New York, ISBN-13: 978-1848729827, Pages: 256.

Morikawa, T., T. Yamamoto, D. Dissanayake, N. Sanko and S. Kurauchi et al., 2003. Travel behavior analysis and its implication to urban transport planning for Asian cities: Case Studies of Bangkok, Kuala Lumpur, Manila and Nagoya. Master Thesis, Nagoya University, Nagoya, Japan.

Petersen, R. and C. Schafer, 2004. Sustainable Transport: A Policy-Maker's Guide to Developing Cities. In: Urban Spatial Planning and Urban Transportation, Petersen, R. and C. Schafer (Eds.). GIZ Publisher, India, pp: 1-13.

Pucher, J. and J.L. Renne, 2003. Socioeconomics of urban travel: Evidence from the 2001 NHTS. Transp. Q., 57: 49-77. 
Santoso, S., 2014. SPSS 22 from Essential to Expert Skills. PT. Elex Media Komputindo, Jakarta, Indonesia,.

Sempere, J. and J. Riechmann, 2000. [Sociology and Environment]. Editorial Síntesis SA, Madrid, Spain, ISBN:9788477387534, Pages: 348 (In Spanish).

Soehodho, S., F. Rahadiani and Komarudin, 2012. Transport mode choice by land transport users in Jabodetabek (Jakarta-Bogor-Depok-TangerangBekasi): An Urban ecology analysis. Proceedings of the 2nd International Conference on Electrical, Electronics and Civil Engineering (ICEECE'2012), April 28-29, 2012, Gosyen Publishing, Yogyakarta, Indonesia, pp: 177-181.
Steg, L. and R. Gifford, 2005. Sustainable transportation and quality of life. J. Transp. Geogr., 13: 59-69.

Steg, L., 2003. Can public transport compete with the private car? IATSS Res., 27: 27-35.

Steg, L., 2005. Car use: lust and must. Instrumental, symbolic and affective motives for car use. Transp. Res. Part A: Policy Practice, 39: 147-162.

Timmermans, H., P.V.D. Waerden, M. Alves, J. Polak and S. Ellis et al., 2003. Spatial context and the complexity of daily travel patterns: An international comparison. J. Transp. Geogr., 11: $37-46$. 